\title{
The Structural Equation Model of Ecological Footprint and Inspiration of Public Mind Affecting Student's Pro-Environmental Behaviour
}

\author{
Sapphasit Kaewhao, Lecturer, Department of Environmental Science, \\ Faculty of Science and Technology Rajabhat Maha Sarakham University, \\ Mahasarakham 44000, Thailand, Email: Sapphasit1981@gmail.com
}

The research objectives were to verify the structural equation model of Ecological Footprint (EF) and Public Mind Inspiration (PMI) affecting the Pro-environmental Behaviour (PB) of undergraduate students. The samples were 400 undergraduates of Rajabhat Mahasarakham University, collected by The MultiStage sampling technique. The research tool was a five-rating scaled questionnaire. The data was analysed by employing descriptive statistics and the factor analysis with LISREL Mplus. The results revealed that EF and PMI were able to explain the variation of $\mathrm{PB}$ with 72.00 percent. EF had the most direct effect on PB with an effect of 0.45 , subsequently was PMI with an effect of 0.42. Moreover, EF had an effect on PMI with an effect of 0.31 and was able to predict the variation of PMI with 75.00 percent. The structural equation model of EF affecting PB through PMI verified the proposed model. It fitted with all observed variables in line with the criteria of a ChiSquare/df value less or equal to 1.929 and it was less than or equal to $5.00\left(\chi^{2} / \mathrm{df} \leq 5.00\right)$. RMSEA (Root Mean Square Error Approximation) equalled 0.045 (RMSEA < 0.05) and RMR (Root Mean Square Residual) equalled 0.024 (RMR < 0.05) and included the index level of model congruent value of Goodness of Fit Index (GFI) equal to 0.95, and Adjust Goodness of Fit Index (AGFI) equal to 0.93, which are between 0.90-1.00.

Keywords: Ecological Footprint, Inspiration of Public Mind, Pro-Environmental Behaviour 


\section{INTRODUCTION}

Persuading humans to practice pro-environmental behaviour is challenging work for scientific and social academics. Changing human behaviour in any aspect is hard work since high individual characters include numerous factors whether it be their different environment, culture, lifestyles, belief, attitude, awareness, and intelligence (Thiengkamol, 2011e, Wikipedia, 2019). Recently, there has been an increased interest in the areas of health, education, criminology, environment such as energy aspect, consumption pattern and sustainable development with the hope that understanding behavioural change will improve the quality of human life (Thiengkamol, 2016; Wikipedia, 2019). In order to cover the challenge of pro-environmental behaviour, the insight understanding human behaviour patterns, particular in conserving the environment and ecosystem, requires understanding other than the environmental knowledge of ecological footprint and public mind inspiration (Mukpradub et al., 2016; Thiengkamol, 2016).

The Ecological Footprint (EF) has been recognised as the human activity impacts measured in terms of the area of biologically productive land and water required to produce the goods consumed and to assimilate the wastes generated by fossil and nuclear fuel consumption. Or it is the amount of the environment necessary to produce the goods and services necessary to support a particular lifestyle (Wackernagel et al., 2002; Monfreda et al., 2004; McGinley, 2012; WWF, 2019).

EF is also a measure of sustainability because recently, stakeholders from around the world are focused more on ways to encourage sustainability and decrease environmental degradation by highlighting the inequities within and between people and nations for natural resource consumption including between the poor and the rich. Therefore, the ecological footprint is proposed as a useful tool that can help to raise public awareness and shape a healthier and more sustainable future elucidating on the importance of ecological footprint and its importance in improving environmental standards (Sonu et al, 2011; Gautami, 2010; WWF, 2019).

Inspiration of Public Mind Inspiration (PMI), proved by Thiengkamol and her colleagues research works, covers various topics of research including health, environment and natural resources knowledge, life cycle assessment knowledge, and education. These relate to environmental conservation behaviour (Thiengkamol, 2016). PMI consists of a key person to act as a role model, an impressive environment, an impressive event, and inspiration from participation of the media. As such, she and her colleagues examined an imperative approach for creating the inspiration of public mind or a public consciousness of environmental conservation. This approach was taken as most people do not recognise environmental problems in day to day living as they are challenged with more pressing primary needs, in particular to earn and so on (Thiengkamol, 2012e; Saisunantharom et 
al., 2013a; Suensing et al., 2013b; Thiengkamol, 2016). Therefore, they will not be aware of an environmental crisis until it in their backyard, affecting their quality of life. Only when people are confronted with serious forms of pollution, such as air pollution or water pollution and so on, are they forced to pay attention to environmental problems (Mongkonsin et al, 2013b; Kotchakote et al., 2013a; Kotchakote et al., 2013b; RiveraRentas, et al., 2007; Schmidt, 2007). In this context inspiration is completely different from motivation as a person who supports, acts and practices environmental conservation with the drive gained from an inspired desire will be pleased to do so in support of the local community and national population without the need for further rewards such as money, honour or admiration. The inspiration for such an act may have been acquired from a leading role model, an impressive environment, an impressive event and / or inspiration from participation of the media (Thiengkamol, 2011e; Saisunantharom et al., 2013a; Suensing et al., 2013b; Hoerisch, 2002).

The purpose of this research is to introduce EF knowledge for the undergraduate students to understand the importance of EF and PMI pro-environmental behaviour behaviours including consumption, energy conservation, waste management, recycling, travelling and environmental knowledge transferring. Finally, they should take responsibility for global warming alleviation (Thiengkamol, 2012e; Saisunantharom et al., 2013a; Suensing et al., 2013b; Thiengkamol, 2016; Schaefer et al., 2006; WWF, 2019; Wackernagel et al., 2005; Mukpradub et al., 2016).

\section{OBJECTIVES}

This research aims to verify the structural equation model of student pro-environmental behaviour concentrating on the objectives as follows:

1. To study the confirmatory variables of ecological footprint (EF) influencing public mind inspiration (PMI) causing the pro-environmental behaviour (PB) of undergraduates.

2. To verify the exogenous latent variable of ecological footprint $(\mathrm{EF})$ with indirect influence causing pro-environmental behaviour (PB) via the endogenous latent variables of public mind inspiration (PMI) of undergraduates.

\section{HYPOTHESES}

- H1: The confirmatory variables of ecological footprint (EF) positively influence the public mind inspiration (PMI) of undergraduates.

- H2: The confirmatory variables of ecological footprint (EF) positively influence the pro-environmental behaviour (PB) of undergraduates. 
- H3: The confirmatory variable of ecological footprint (EF) positively and indirect influences the pro-environmental behaviour (PB) of undergraduates via the confirmatory variables of public mind inspiration (PMI) of undergraduates.

- H4: The confirmatory factors of the PMI positively and directly affect the $\mathrm{PB}$ of undergraduates.

\section{CONCEPTUAL FRAMEWORK}

The conceptual framework referred to the various variables including ecological footprint (EF), public mind inspiration (PMI) and pro-environmental behaviour (PB) of undergraduates in first semester of the academic year of 2019 of Rajabhat Mahasarakham University in the Northeast of Thailand.

Overwhelmingly, the major concepts involved are as follows:

1. Ecological footprint (EF) identifies the knowledge covered by the ecological footprint of shelter, the ecological footprint of food, the ecological footprint of transportation, the ecological footprint of cloth, the ecological footprint of medicine, and the ecological footprint of housing (Sonu et al, 2011; Gautami, 2010; WWF, 2019).

2. Pro-environmental behaviour (PB) is measured by the observed variables of consumption behaviour, energy conservation behaviour energy, waste management behaviour, recycling behaviour, travelling behaviour and environmental knowledge transferring behaviour. The observed variable of conservation behaviour is reflected in daily living practices by consuming green products to conserve the environment and ecological system (Murray, 2005; Saisunantharom et al., 2013a; Ertz et al., 2016). Energy conservation behaviour means to reduce energy use in the home and promote energy conservation at educational institutes including at public places with the willingness of people to use green energy and contribute to the wellbeing of the environment. (Sangroya, 2017; Thiengkamol, 2016). Waste management behaviour refers to waste reduction, reuse, and recycling. These behaviours are related to environmental values, knowledge, and are concern-based. Thus the young generation in education in schools and universities are acknowledged on these waste management behaviours (Barr, 2007; Mukpradab et al., 2016). In addition, recycling behaviour is reflected as essential behaviour to conserve environmental quality and decrease the environmental impact (Barr, 2007; Mukpradab et al., 2016; Thiengkamol, 2016). Travelling behaviour means the important concern of performing travel with decrement of energy consumption and green activity such as the promotion of walking or bicycling to school and university or car pooling. Knowledge transferring behaviour is an ordinal concept of environmental education that emphasises educating environmental knowledge, values, beliefs, awareness and skills for all (Thiengkamol, 2016; Tungchuvong et al., 2020). This is pertinent to the 
study of entrepreneur's pro-environmental behaviours and the mediating role of corporate social responsibility (Jitrumluek et al. 2019) to raise the peoples' beliefs and concerns.

3. Public Mind Inspiration (PMI), long-established by Thiengkamol, (2016), is an essential mediating latent variable or endogenous variable covered by the consequent observed variables of self-public mind, role model impression, event impression, environment impression and media reception. PMI is dissimilar from motivation, as the reasoning of the motivation is to necessitate money, payments, approbation, and some reciprocals. Nevertheless, the self-public mind arises from insight in the mind and the point of view of genuineness or voluntary support for a community and/or an organisation deprived of demanding any reimbursements (Mukpradab et al., 2016; Thiengkamol, 2016; Jitrumluek et al. 2019; Tungchuvong et al., 2020).

\section{METHODOLOGY}

The research method was conducted by survey research with undergraduates as participants to collect data about their status and their understanding about the relationship among the confirmatory variable variables of ecological footprint (EF), public mind inspiration (PMI) and pro-environmental behaviour (PB).

\section{Participants}

Participants are a population of 11,512 undergraduates in the first semester of the academic year of 2019 of Rajabhat Mahasarakham University in the Northeast of Thailand. The samples used a multi-stage sampling technique from the population group by employing Yamane's formula with a confidence level of 0.05 obtaining a size of 400 samples (Schonlau, Fricker \& Elliott, 2002). When considering sample status, it was found that the majority of the sample group was female, 220 (55.00\%), most of them paid respect to Buddhism, 390 (97.50\%), and had a resident status of inside municipality, 240 (60.00\%). The majority had a nuclear family, 235 (58.75\%). They travelled by motor-bicycle, 290 $(72.505 \%)$, and had a mean age of 20.45 years. Moreover, the majority had an income per month with a mean of $6,415.56$ baht.

\section{Research tool}

The research tool was a questionnaire comprised of sample status and content variable with a 5 five-point rating scale comprised of the terms 'strongly disagree as 1 point, agree as 2 points, undecided agree as 3 points, agree as 4 points, and strongly agree representing 5 points'. The structural validity of the questionnaire was proved by Item Objective Congruent (IOC) from 5 experts in the fields of ecology, environmental education, social science and social research methodology. The reliability was determined by Cronbach's Alpha formula. 
The ecological footprint contained 42 items, public mind inspiration contained 35 items, pro-environmental behaviour contained 42 items, and whole questionnaire consisted 161 items. Their reliabilities were $0.856,0.874,0.931,0.927$ and 0.938 respectively. The earlier quality valuation of the questionnaire report indicated that it was appropriate to collect the data for the research samples. The instrument contents used the various latent variables constructed including:

1) ecological footprint (EF) including X1- ecological footprint of shelter, $X 2$ - ecological footprint of food, X3- ecological footprint of transportation, X4- ecological footprint of cloth, X5- ecological footprint of medicine, and X6- ecological footprint of housing, a total of 49 items.

2) pro-environmental behaviour community forest conservation behaviours (PB) composing of Y1- consumption behaviour, Y2- energy conservation behaviour, Y3- waste management behaviour, Y4- recycling behaviour, Y5- traveling behaviour, and Y6 environmental knowledge transferring behaviour, a total of 42 items.

3) inspiration of the public mind (IPM) covering Y7- self-public mind, Y8- role model impression, Y9- event impression, Y10- environment impression and Y11- media reception with a total of 42 items.

Each latent variable was constructed and proved by using the confirmatory factor analysis (CFA) to verify the congruent issues of each item. Moreover, the number of items used to measure the observed variable requires at least three items for each variable. Another criterion for each latent variable required at least three observed variables. Thus, the number of items used to qualify each observed variable and latent variables constructs are presented in Table 1:

Table 1. Number of Items and Latent Variable Constructs

\begin{tabular}{l|l|c}
\hline \multicolumn{1}{c|}{ Constructs } & \multicolumn{1}{c|}{ Variables } & Number of Items \\
\hline Knowledge of Community Forest & X1-ecological footprint of shelter & 49 \\
Conservation (KOC) & X2- ecological footprint of food & \\
& X3- ecological footprint of transportation & \\
& X4- ecological footprint of cloth & \\
X5- ecological footprint of medicine & \\
Pro-environmental Behaviour & X6- ecological footprint of housing & \\
(PB) & Y1- consumption behaviour & \\
& Y3- energy conservation behaviour & \\
& Y4- recycling behaviour & \\
& Y5- travelling behaviour & \\
& Y6 environmental knowledge transferring behaviour & \\
\hline \hline
\end{tabular}


International Journal of Innovation, Creativity and Change. www.ijicc.net

Volume 15, Issue 7, 2021

\begin{tabular}{l|l|c}
\hline & & \\
Inspiration of the Public Mind & Y7- self-public mind & \\
(IPM) & Y8- role model impression & \\
& Y9- event impression & \\
& Y10- environment impression & \\
& Y11- media reception & 42 \\
\hline \hline
\end{tabular}

\section{Data Collection}

The research instrument was the questionnaire, and it was used for data gathering. The survey research was conducted by using the questionnaire to gather 400 undergraduates with the multi-stage sampling (Schonlau, Fricker \& Elliott, 2002) from 11,512 undergraduates in the first semester of the academic year of 2019 of Rajabhat Mahasarakham University of the North-Eastern region of Thailand.

\section{Data Analysis}

The descriptive statistics were frequency, percentage, mean and standard deviation. Structural Equation Model (SEM) was used for model confirmation with LISREL version 8.30 by considering (i) the Chi- Square value was not statistically significant at a level of 0.01 or a Chi-Square/df value less or equal to 5; (ii) RMSEA (Root Mean Square Error Approximation) and RMR (Root Mean Square Residual) values less than 0.05 including index level of model congruent value; (iii) GFI (Goodness of Fit Index), index level of model congruent value, and AGFI (Adjust Goodness of Fit Index) between 0.9-1.00.

\section{RESULTS}

\section{Results of the Effect Among Variables in the Model in Terms of Direct and Indirect Effect}

The ecological footprint (EF) and public mind inspiration (PMI) had effects on proenvironmental behaviour (PB) of undergraduates as per the following:

1. Confirmatory factors of the EF directly affected PMI with a statistically significant level of 0.01 with an effect of 0.32 responses to $\mathrm{H} 1$. EF directly affected the PB of undergraduates with a statistically significant level of 0.01 with an effect of 0.45 . This answers $\mathrm{H} 2$, and indirectly affected the $\mathrm{PB}$ of undergraduates with a statistically significant level of 0.05 with an effect of 0.13 responses to $\mathrm{H} 3$. 
2. Confirmatory factors of the PMI directly affected the PB of undergraduates with a statistically significant level of 0.01 with an effect of 0.41 . This answers H4.

The structural model confirmatory factors of the component analysis of the EF and the PMI had effects on the PB of undergraduates with variation of $72.00 \%$. The structural equation can be written as demonstrated in the following equation (1).

$$
\begin{aligned}
& \mathrm{PB}=0.45^{*} \mathrm{EF}+0.41 * \mathrm{PMI} \\
& \mathrm{R}^{2}=0.72
\end{aligned}
$$

Equation (1) factors that had the most effect on PB was the EF with 0.45 , subsequently was PMI with an effect of 0.41 , which was able to explicate the variation of the PB of undergraduates with 72.00 percent.

Considering the confirmatory factor the PMI of undergraduates, it demonstrated that the EF had an effect on the PMI of undergraduates with 0.32. It is able to explicate the variation of the P.MI with $75.00 \%$. The structural equation can be written as the following.

$$
\begin{aligned}
& \mathrm{PMI}=0.32 * \mathrm{EF}+ \\
& \mathrm{R}^{2}=0.75
\end{aligned}
$$

Equation (2) factors that had the most effect on PMI was EF and it is able to explain the variation of the PMI of undergraduates with 75.00 percent.

The results of the exogenous variable had an effect on the endogenous variables with direct and indirect effects that are established in picture 1 and table 2. 
International Journal of Innovation, Creativity and Change. www.ijicc.net

Volume 15, Issue 7, 2021

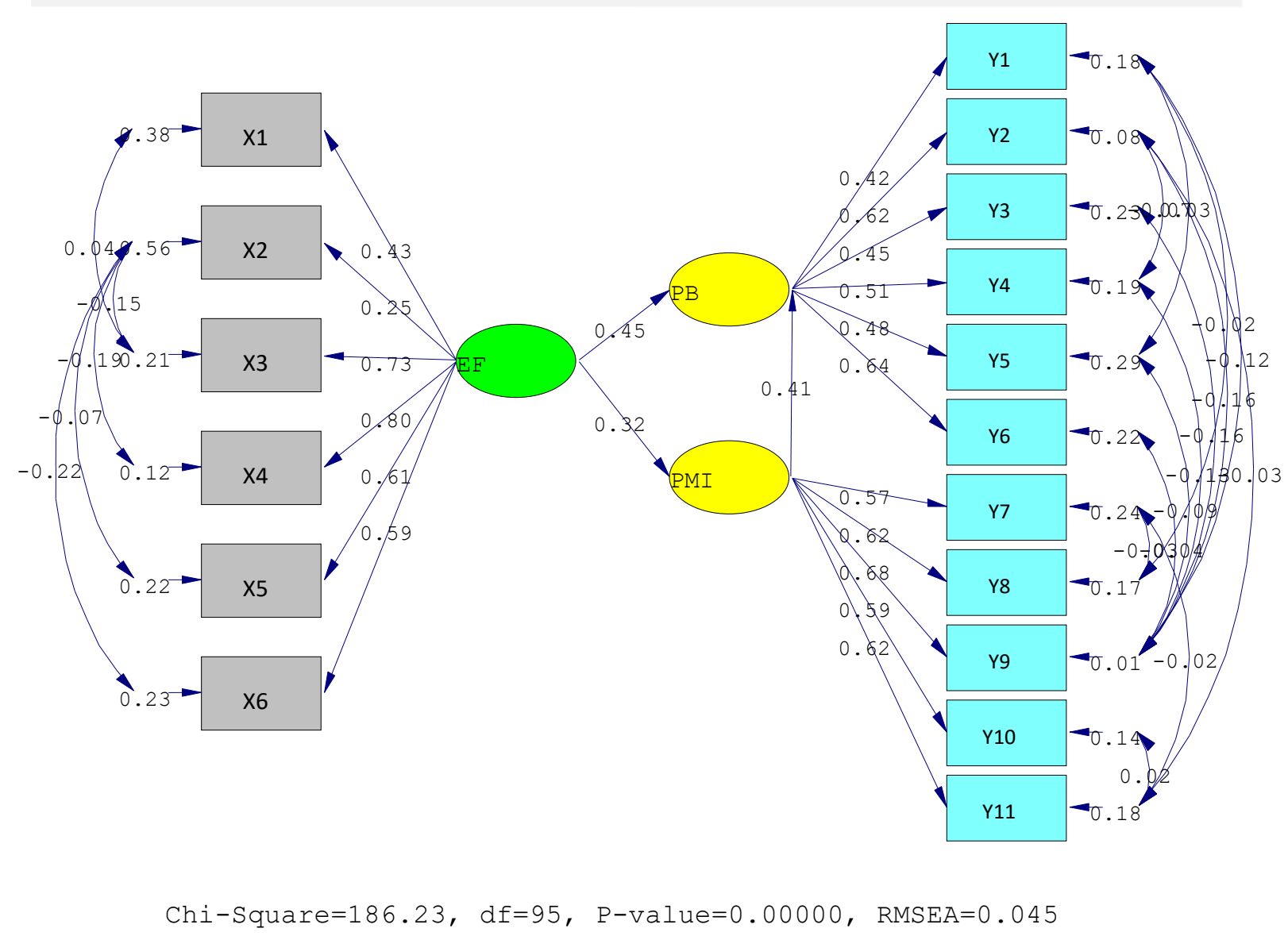

Picture 1. Structural Equation Model of EF and PMI affecting PB

Table 2. Direct and Indirect Effect of EF Affecting PB through PMI

\begin{tabular}{|c|c|c|c|c|c|c|}
\hline \multirow{3}{*}{$\begin{array}{l}\text { Causal } \\
\text { variable }\end{array}$} & \multicolumn{6}{|c|}{ Result variables } \\
\hline & \multicolumn{3}{|l|}{ PMI } & \multicolumn{3}{|l|}{ PB } \\
\hline & TE & IE & $\mathrm{DE}$ & TE & IE & $\mathrm{DE}$ \\
\hline $\mathrm{EF}$ & $\begin{array}{l}0.32 * * \\
(0.012)\end{array}$ & - & $\begin{array}{l}0.32 * * \\
(0.012)\end{array}$ & $\begin{array}{l}0.58 * * \\
(0.004)\end{array}$ & $\begin{array}{l}0.13^{*} \\
(0.008)\end{array}$ & $\begin{array}{l}0.45 * * \\
(0.001)\end{array}$ \\
\hline PMI & - & - & - & $\begin{array}{l}0.41 * * \\
(0.033)\end{array}$ & - & $\begin{array}{l}0.41 * * \\
(0.033)\end{array}$ \\
\hline \multicolumn{3}{|c|}{$\chi^{2}=186.23 ; \mathrm{df}=95$} & \multicolumn{2}{|c|}{$\mathrm{CN}=264.78$} & \multicolumn{2}{|c|}{$\chi^{2} / d f=1.960$} \\
\hline $\mathrm{GFI}=0.95$ & \multicolumn{2}{|c|}{$\mathrm{AGFI}=0.93$} & \multicolumn{2}{|c|}{ RMSEA $=0.045$} & \multicolumn{2}{|c|}{$\mathrm{RMR}=0.024$} \\
\hline
\end{tabular}

$* \mathrm{P}$-value $<0.05, * * \mathrm{P}$-value $<0.01$

However, it might be concluded that EF as a latent variable plays a critical role for the undergraduate in performing PB. Therefore, the structural equation model of EF affecting PB through PMI was verified in the proposal model. It fitted with all observed variables by corresponding to measures of Chi-Square/df value less or equal to 1.960 and it was less than or equal to 5.00. RMSEA (Root Mean Square Error Approximation) was equal to 
International Journal of Innovation, Creativity and Change. www.ijicc.net

Volume 15, Issue 7, 2021

0.045 (RMSEA < 0.05) and RMR (Root Mean Square Residual) was equal to 0.024 (RMR < 0.05) including an index level of model congruent value of Goodness of Fit Index (GFI) equal to 0.95, and Adjust Goodness of Fit Index (AGFI) equal to 0.93 which are between 0.90-1.00.

To understand the statistical symbols, the guide descriptions are as follows:

p characterises Probability value

df characterises Degree of freedom value

GFI characterises Goodness of fit index value

AGFI characterises Value of adjust goodness of fit index

$P \quad$ characterises statistically significant level

RMSEA characterises Value of root mean square error of approximation

RMR characterises Value of root mean square residual

$C N$ characterises Critical number value

DE characterises Direct effect value

IE characterises Indirect effect value

TE characterises Total effect value

Variables

EE characterises Ecological footprint

PMI characterises Public mind inspiration

$P B \quad$ characterises

\section{CONCLUSION}

From the research findings, it can be concluded as follows:

1. Confirmatory factors of the EF directly affect PMI with a statistically significant level of 0.01 , directly affect the pro-environmental behaviour (PB) of undergraduates with a statistically significant level of 0.01. 0.45, and indirectly affect the PB of undergraduates with a statistically significant level of 0.05 .

2. Confirmatory factors of the public mind inspiration (PMI) directly affect the PB of undergraduates with a statistically significant level of 0.01 . It is able to explain the variation of endogenous variable of PMI; in turn, it also able to explain the PB of undergraduates at the predictive level of $72.00 \%$, and the variation of endogenous factor of the inspiration of PMI at $75.00 \%$.

\section{DISCUSSION}

The results indicated that understanding the concept of Ecological Footprint (EF) was predicted by the 6 observed variables of ecological footprint of food, ecological footprint 
of transportation, ecological footprint of cloth, ecological footprint of medicine, ecological footprint of housing and ecological footprint of shelter, with predicting power of $0.75,0.72$. $0.70,0.60,0.58$, and 0.42 respectively. In addition, EF also directly affect the proenvironmental behaviour with an effect of 0.45 . It is a moderate effect, therefore it might be concluded thus EF plays a critical role in changing the pro-environmental behaviours in line with the study of Mukpradab and others (Mukpradab et al., 2016) They revealed that ecological footprint $(\mathrm{EF})$ had the most effect on environmental conservation behaviour with an effect of 0.48. Besides, pro-environmental behaviour predicted environmental knowledge transferring behaviour, energy conservation behaviour, recycling behaviour, waste management behaviour, consumption behaviour and traveling behaviour with prediction power of $0.63,0.61,0.53,0.48,0.45$, and 0.42 respectively. The results pointed out that $\mathrm{EF}$ is an essential factor that is able to enhance pro-environmental behaviours of undergraduates to form a good pattern of behaviour as a change agent to transfer their environmental knowledge to their friends, family members, and others people in university and society. The results were in line with Thiengkamol and her colleagues (Thiengkamol, 2012e; 2012a; Kotchachote et al., 2013a; Mongkonsin et al., 2013b; Saisunantharom et al., 2013a; Suebsing et al., 2013b).

Furthermore, the public mind inspiration had a direct effect on the pro-environmental behaviours of undergraduates with an effect of 0.41 whilst regarding to forecasting the correlation of the observed variables of the self-public mind, role model impression, event impression, environment impression, and media reception. These were harmonious to diverse studies of Thiengkamol and her colleagues (Kotchachote et al., 2013a; Saisunantharom et al., 2013a; Suebsing et al., 2013b; Thiengkamol, 2012e; Mukpradub et al., 2016) where these studies also revealed that the public mind inspiration plays an important role in promoting pro-environmental behaviours of undergraduates directly. This indicated that public mind inspiration affects pro-environmental behaviours whether it be consumption behaviour, energy conservation, waste management behaviour, recycling behaviour, traveling behaviour or knowledge transferring and supporting for environmental conservation.

Thus, this research results indicated that university administrators and academic teams can use ecological footprints cooperatively in the teaching-leaning process and use it to challenge and inspire the undergraduate to pay attention and play a role as a change agent through environmental knowledge and by integrating the public mind concept to reach a sustainable development. 
International Journal of Innovation, Creativity and Change. www.ijicc.net

Volume 15, Issue 7, 2021

\section{REFERENCES}

Barr, S. (2007). Factors Influencing Environmental Attitudes and Behaviours: A U.K. Case Study of Household Waste Management. Environment and Behaviour, 39(4): 435-473

Ertz, M., Karakas, F., Sarigollu, E. ( 2016). Exploring pro-environmental behaviours of consumers: An analysis of contextual factors, attitude, and behaviours, Journal of business research, 69(10): 3971-3980

Gautami S. Tondapu. (2010). "Ecological Footprint and Sustainable Development" Express. Retrieved from: http://works.bepress.com/gautami_tondapu/1

Hoerisch, H. (2002). A Comparative Study on Environmental Awareness and EnvironmentallyBeneficial Behaviour in India. CMS ENVIS Centre. Retrieved $\begin{array}{llll}\text { from the } & \text { October } & 2009,\end{array}$ http://www.cmsindia.org/cmsenviscentre/researchstudy/beneficial.pdf

Jitrumluek, P., Falcioni, R., Thiengkamol, N. and Thiengkamol, T.K. (2017). Entrepreneur's Pro-Environmental Behaviour: The Mediating Role of Corporate Social Responsibility. The Journal of Behavioural Science 14(1): 14-27.

Kotchachote, Y., Thiengkamol, N., Thiengkamol Khoowaranyoo, T. (2013a). Casual Relationship Model of Forest Fire Prevention. European Journal of Scientific Research, 104 (3):519-532.

McGinley, M. (2012). Exponential Growth. Encyclopedia of Erath. Retrieved on 9 Dec 2014, from: http://www.eoearth.org/view/article/152715/

Monfreda, C., Wackernagel, M., Deumling, D. (2004). Establishing national natural capital accounts based on detailed ecological footprint and biological capacity assessments. Land Use Policy 21 (3), 231-246.

Mongkonsin, Thiengkamol, N., \& Thiengkamol, T. (2013b). Causal Relationship Model of Flood Response Behaviour. Mediterranean Journal of Social Sciences, 4 (1):587-598.

Mukpradab, P. Thiengkamol, N., Thiengkamol Khoowaranyoo, T. (2016). Model of Factors Affecting Environmental Conservation Behaviour of High School Student. Journal of Kasem Bundit, 17(1): 44-55.

Rivera-Rentas, A., Vilches, M., Davila, E., Rebollo, C., Rodriguez, M. Garcia, S. and Seguinot, S. (2007). Environmental awareness through integration of research and education: a case study from two elementary public schools in Puerto Rico. International Journal of Environment and Pollution 2007 - Vol. 31, No.3/4 pp. 359370. Retrieved from the web November 3, 2009 http://www.inderscience. $\mathrm{com} / \mathrm{search} /$ index.php? action=record\&rec $\mathrm{id}=16502 \&$ prevQuery $=\& \mathrm{ps}=10 \& \mathrm{~m}=$ or .

Saisunantharom, S. Thiengkamol, N., Thiengkamol, C. (2013a). Casual Relationship Model of Biodiversity Conservation. European Journal of Scientific Research, 104 (3):460-474.

Sangoya, D. (2017). Factors influencing buying behaviour of green energy consumer Journal of Cleaner Production, 151:393-405 
International Journal of Innovation, Creativity and Change. www.ijicc.net Volume 15, Issue 7, 2021

Schaefer, F., Luksch, U., Steinbach, N., Cabeca, J, \& Hanauer, J. (2006). Ecological Footprint and Biocapacity: The World ability to regenerate resources and absorb waste in a limited time period. Luxembourg: Office for Official Publications of the European Committees.

Schmidt, J. E. (2007). From Intentions to Actions: The Role of Environmental Awareness on College 16Students. UW-L Journal of Undergraduate Research X (2007). Retrieved from the web October 2, 2009. http://www.uwlax.edu/urc/JURonline/PDF/2007/schmidt.pdf.

Sonu. G., Binod, P., Sonika, G.R. (2011). Ecological Footprint: A tool for measuring Sustainable development. International Journal of Environmental Sciences, 2(1):140-144.

Suebsing, S., Thiengkamol, N., Thiengkamol, C. (2013b). Causal Relationship Model of Forest Conservation. European Journal of Scientific Research, 115 (2):292-304.

Thiengkamol, N. (2011e). Environment and Development Book. (4th ed.).Bangkok: Chulalongkorn University Press.

Thiengkamol, N. (2012e). Causal Relationship Model of Environmental Education. Mediterranean Journal of Social Sciences, 3 (11), 11-18.

Thiengkamol, N. (2016). Theory Development with LISREL Research. Bangkok: Chulalongkorn Printing House.

Tungchuvong, L., Thiengkamol, N., Thienkamol., T.K. (2020). The Model Development of the Community Forest Conservation In Thailand. International Journal of Advanced Science and Technology, 29(5): 1264-1274.

Wackernagel, M., Monfreda, C., Moran, D., Wermer, P., Goldfinger, S., Deumling, D., Murray, M. (2005). National Footprint and Biocapacity Accounts 2005: the Underlying Calculation Method. Global Footprint Network, Oakland.

Wackernagel, M., Schulz, N.B., Deumling, D., Linares, A.C., Jenkins, M., Kapos, V., Monfreda, C., Loh, J., Myers, N. (2002). Tracking the ecological overshoot of the human economy. Proceedings of the National Academy of Sciences of the United States of America 99, 9266-9271.

Wikipedia. (2019). Behaviour change (individual). Retrieved on 9 Dec 2014, from: https://en.wikipedia.org/wiki/Behaviour_change_(individual)

WWF. (2019). Ecological Footprint. Retrieved from: https://wwf.panda.org/knowledge_hub/teacher_resources/webfieldtrips lecological_balance/eco_footprint/ 